\title{
Academic Performance of Introductory Psychology Students: The Importance of Critical Thinking
}

\author{
Kerry A. Schwanz ${ }^{*}$ Megan McIlreavy \\ Department of Psychology, Coastal Carolina University, Conway, South Carolina, USA \\ *Corresponding author: kaschwan@coastal.edu
}

Received April 27, 2015; Revised April 30, 2015; Accepted May 04, 2015

\begin{abstract}
The purpose of this study was to examine the importance of critical thinking for academic performance of students enrolled in introductory level psychology courses. Critical thinking skills and academic self-efficacy were significantly related to how students performed at the end of an introductory psychology course. Critical thinking skills along with high school GPA were the best predictors of student learning at the end of the course. Critical thinking was not predictive of overall academic performance as measured by cumulative GPA at the end of the semester. Instead, high school GPA emerged as the sole predictor of cumulative GPA, accounting for $22 \%$ of the variance. Results indicated no significant difference in critical thinking, academic self-efficacy, or final exam performance at the end of the semester for students enrolled in psychology courses taught using two different methods; Team-Based Learning vs. a traditional lecture format. The implications for these findings as they relate to academic performance and overall student learning in higher education are discussed.
\end{abstract}

Keywords: critical thinking, academic self-efficacy, team-based learning, college students

Cite This Article: Kerry A. Schwanz, and Megan Mcllreavy, "Academic Performance of Introductory Psychology Students: The Importance of Critical Thinking." Research in Psychology and Behavioral Sciences, vol. 3, no. 2 (2015): 25-31. doi: 10.12691/rpbs-3-2-2.

\section{Introduction}

There is an increasing emphasis on the development of critical thinking skills in college students. Being able to think critically with course material and apply it to understand and solve real-world problems is viewed as an important learning outcome of higher education $[10,16]$. In today's world, technology makes it possible for students to access information instantaneously with very little skill or effort being required to do so. However, being able to find information and facts quickly does not mean that students are able to comprehend it, think critically about it, or use it appropriately to solve problems and to make important decisions.

The American Philosophical Association's definition of critical thinking skills has been widely accepted by philosophers, educators, and scientists since its development in 1990. According to this definition, critical thinking skills are comprised of six components that are used to make judgments and decisions; interpretation, analysis, evaluation, inference, explanation, and selfregulation of information [6]. These higher-level thinking skills are being emphasized more in student learning outcomes for courses taught at the college level. Furthermore, critical thinking skills reflect important aspects of college student learning that may not only enhance student understanding of the knowledge and skills specific to their discipline but their ability to think and learn in general.
We were interested in investigating the importance of critical thinking for students' academic performance. More specifically, we sought to understand critical thinking as a predictor of academic performance and also one to be developed within an introductory psychology course.

\section{Literature Review}

Because there is such value being placed on fostering critical thinking in higher education $[3,16]$ it is worthwhile to investigate whether or not critical thinking predicts important educational outcomes for college students. The relationship of critical thinking skills to academic achievement in college students has been investigated but results are not consistent in terms of the magnitude of this relationship. Some researchers have found that measures of overall critical thinking skills accounted for less than $1 \%$ of the variance in students' GPAs [8], while others have found moderate correlations between overall critical thinking skills and GPA [3]. Small positive correlations between critical thinking disposition, which represents an individual's willingness and propensity to use critical thinking skills and college GPA have also been reported [16]. Perhaps the differences in the magnitude of the relationship between critical thinking and GPA found in the literature could be due to researchers using different tests to measure critical thinking or different methods to gather information about student GPA such as self-report versus objective measures. 
Other variables besides past achievement and cognitive variables such as critical thinking may be important for predicting college students' academic performance. Traditionally, universities have used scores on standardized aptitude or achievement tests such as the SAT or the ACT along with past achievement (i.e., high school GPA) to assess readiness for college and to make admissions decisions [13]. Researchers have generally found that these traditional predictors often yield mediumsized correlations with college GPA and are therefore useful in making accurate decisions about college admissions [13,14]. Richardson, Abraham, and Bond [14] conducted a systematic review of 13 years of research on correlates of university students' academic performance. Through meta-analysis, these researchers discovered three overall categories of variables that emerged from the studies they reviewed. The three overall categories were demographic variables (i.e., gender and SES), measures of cognitive capacity or prior academic performance (i.e., SAT, ACT, HS GPA), and psychosocial variables such as personality traits and motivational factors. Richardson et al. also emphasized that when trying to predict academic performance, it is important to assess various constructs upon which people differ besides focusing only on cognitive and academic variables. Academic self-efficacy was one of the non-cognitive psychosocial variables that correlated moderately with college GPA. Robbins, Lauver, Le, Davis, Langley, \& Carlstrom [15] conducted a metaanalysis of 109 studies to examine the relationship of psychosocial factors to college students' cumulative GPA and retention. Among the nonacademic variables investigated in this study such as academic motivation, social support, general self-concept, financial support, and institutional size, academic self-efficacy emerged as the best predictor of both GPA and retention. Academic selfefficacy is a construct derived from Bandura's [2] social learning theory that reflects "self-evaluation of one's ability and/or chances for success in the academic environment” [[15], p. 267]. The findings from both of these recent meta-analyses and other past research dating back to the late 70's linking academic self-efficacy to college performance $[1,5,12,17]$ suggest that over time academic self-efficacy has been a worthwhile variable to consider when investigating college students' academic success. It seems that past research supports the importance of both critical thinking and academic selfefficacy to college student learning.

Various instructional techniques have been developed to improve critical thinking and student learning in general. A thorough discussion of these techniques is beyond the scope of this paper but it is important to note that at the college level, most textbooks now include exercises, activities, discussion questions, and other resources for instructors to utilize in order to attempt to improve students' critical thinking. Instructors may also develop their own techniques to foster critical thinking and professional development training at many universities often include components that address effective teaching. However, it is not possible to know for sure, whether the professional development trainings, instructor developed materials, or the resources provided by textbooks have any true impact on improving students' critical thinking or learning in general. According to Cotter and Tally [4] the materials advertised by textbook companies as being useful for improving critical thinking skills often lack empirical support or a strong theoretical basis for this claim. Cotter and Tally studied the improvement of critical thinking skills in a group of college students enrolled in a lifespan developmental psychology course who completed critical thinking assignments from their textbooks as part of their course requirements. These researchers indicated that completion of critical thinking assignments did not improve students' critical thinking skills as measured by their performance on the California Critical Thinking Skills Test [CCTST; 6] and that student critical thinking scores actually declined over the semester. Perhaps it takes more radical changes to overall teaching methods or course design to render significant changes in students' critical thinking and performance rather than incorporating new materials and activities into existing methods.

Team-Based Learning (TBL) is a teaching method developed by Dr. Larry Michaelsen that fosters critical thinking in students by teaching them how to think actively with course content and to apply it to understand and solve real-world problems. Using the TBL method, instructors are able to shift the focus of class time from note-taking and learning basic facts to team-centered discussions and application activities. With this method, students have the responsibility to come to classes having read course material and to contribute actively to course discussions and activities. Rather than lecturing about the course material, the instructor's role is to serve as the content expert and as a facilitator of the discussions and problem-solving activities. Continuous assessment is also an important component of TBL whereby students' knowledge of content and ability to think critically with the course material is regularly assessed on both an individual and team basis. For a complete description and discussion of the TBL method please see Michaelsen, Knight, and Fink [11]. Team-Based Learning has primarily been utilized in graduate level medical and business school settings, therefore, few studies have focused on the use of TBL in undergraduate courses. More specific to the discipline of psychology, Haberyan [9] investigated the usefulness of the TBL approach in an undergraduate industrial/organizational psychology course. Students in the I/O course taught using the TBL method answered significantly more questions related to content knowledge on a posttest than on a pretest, suggesting that learning had occurred over the semester. When compared to students who had completed the course during the prior semester that had been taught using a traditional lecturebased method, students in the TBL course earned significantly higher grades. Additionally, analyses of student perceptions of their experience in the TBL course revealed that students reported a preference for TBL over traditional lecture courses, that they believe TBL courses are more interesting and motivating than traditional courses, and that they perform better in TBL courses compared to traditional ones [9]. Findings from this study highlight the benefits of TBL as an instructional technique that fosters learning of course content and provides insight into student perceptions of TBL. However, further research is needed to assess the potential benefits of TBL for enhancing critical thinking skills in undergraduate level students since to our knowledge, this has not specifically been addressed in past studies of TBL. 
The overall purpose of our study was to examine the importance of critical thinking to the academic performance of introductory level psychology students.

Four goals were addressed:

Goal 1. We wanted to examine the relationship of critical thinking and academic self-efficacy to student performance at the end of an introductory psychology course and to overall student learning represented by cumulative GPA.

Goal 2. We wanted to determine which set of variables; critical thinking, academic self-efficacy, SAT, and high school GPA served as the best set of predictors for overall academic performance for introductory level students.

Goal 3. We were interested in exploring whether taking an undergraduate level introductory psychology course taught using the TBL method would enhance student learning of course content, critical thinking skills, and academic self-efficacy compared to taking the course in a lecture-based format.

Goal 4. We were interested in determining whether or not critical thinking skills would change over the course of the semester and if the changes would be different for students enrolled in the lecture or TBL formats. We predicted that critical thinking would increase for all students but that the difference in scores would be larger for students enrolled in the TBL courses.

\section{Method}

\subsection{Participants}

Participants were 132 students (86 women and 41 men) enrolled in introductory psychology classes at a four-year public university in the southeastern United States. The average age of the participants was $19.30(S D=2.12$, range $=17-33$ ). The majority of the students identified their race as Caucasian (59.1\%), while 23.5\% were African American, $3.8 \%$ Hispanic, and 13.6\% selected "other". The sample consisted of freshman (53.9\%) which was the majority of students enrolled in the courses, sophomores (31.8\%), juniors (8.3\%), and seniors (4.5\%), with two students $(1.5 \%)$ choosing not to report their class standing.

\subsection{Materials}

The California Critical Thinking Skills Test (CCTST; Facione, 2000) is a well-established and widely used instrument to assess critical thinking of students enrolled in 4-year institutions. The CCTST consists of 34 multiplechoice items that measure students' ability to infer, explain, analyze, evaluate, and interpret information. The CCTST takes approximately 45 minutes to complete and has acceptable reliability and validity when used with college students [7]. The Academic Self-Efficacy Questionnaire (ASE) is a 32 item instrument designed to measure beliefs about one's capability of achieving a certain goal or standard. It is comprised of six 2 to 4 item subscales that measure student's confidence in their ability to perform in the following areas: memorization, class concentration, understanding, explaining concepts, discriminating concepts, and note taking. Reliability estimates for the subscales (Cronbach's alpha) range from .73 to .87 [12] and the ASE has been shown to be moderately correlated with academic performance [17]. The CCTST was administered during the first two weeks after classes began (pretest) and during the last two weeks of the semester (posttest). The ASE was administered only at the end of the semester (posttest only).

\subsection{Procedure}

Students were enrolled in one of four sections of General Psychology during the same semester taught by two different professors (the first or second authors). Each professor offered two sections of the course taught in two different formats (lecture and modified team-based). The course goals, objectives, student learning outcomes, and exams were identical for both formats. To achieve course goals and objectives in the lecture-based course, the professors used traditional teaching methods such as power point presentations and classroom discussion. In contrast, the modified team-based format involved students being placed into teams of four to six that remained together for the entire semester. Approximately one class period a week, the professors lectured on course material and clarified information that was presented in the textbook. For all of the other class meetings students participated in applied team activities and/or completed learning assessments (quizzes) based on the course reading from the textbook that were taken both individually and in teams.

The TBL format used was a deviation from a traditional TBL model. The purpose for modifying the TBL format was to include more lectures for our introductory level students. The decision to use a modified version of TBL was based on student feedback from previous courses taught by the second author using a strict TBL format. Students reported not understanding some of the course concepts and that they preferred some of class time being spent with the instructor lecturing on the material. Students in all sections completed pre and posttests to assess critical thinking, and academic self-efficacy was assessed at the end of the semester. Traditional exams were also given throughout the semester to both groups to assess content knowledge and a comprehensive final exam was given at the end of the semester to assess overall learning of course content.

Students' demographic and academic information which included gender, age, ethnicity, class standing, SAT scores, high school GPA, and cumulative GPA were obtained from the university's Institutional Research and Assessment Department. The students in the courses were verbally informed that data was being collected as part of their participation in the class and that it would be used for research purposes. Students had the option of opting out of the study at any time by contacting their professors. None of the students chose to withdraw their data from the study. Approval to conduct the study was granted by the university’s Institutional Review Board.

\section{Results}

The overall purpose of our study was to examine the importance of critical thinking to introductory psychology student learning of specific course content and overall academic performance. Goal 1 of the study was to examine the relationship of critical thinking and academic 
self-efficacy to course content knowledge and cumulative GPA for introductory psychology students. Students' performance on a comprehensive final exam served as the measure of learning of course content at the end of an introductory psychology course. Students' pretest and posttest scores on the CCTST and posttest scores on the ASE were correlated with grades on the final exam and with cumulative GPA. The means, standard deviations, and correlation coefficients are presented in Table 1. There was a moderate positive relationship between students' critical thinking skills assessed at the beginning of the semester (pretest) and their final exam grades, $r$ $(124)=.37, p<.001$. There was a positive but small correlation between student's academic self-efficacy ratings reported at the end of the semester and final exam grades, $r(107)=.27, p<.01$. Finally, critical thinking skills assessed at the beginning of the semester were positively related to students' cumulative GPAs, $r$ (127) $=.25, p<.01$.

Goal 2 of the study was to investigate which set of variables would serve as the best predictors of final exam grade and cumulative GPA. Additionally we wanted to determine if critical thinking skills served as a better predictor of students' cumulative GPA than variables such as high school GPA and SAT scores which are traditionally used to predict academic performance for college students. Step-wise multiple regression was used to examine the influence of critical thinking skills (pretest scores), academic self-efficacy (posttest scores), SAT-V, SAT-M, and high school GPA as predictors of final exam grade. Critical thinking pretest scores and not the posttest scores were used for this regression analysis because the posttest scores were not significantly correlated with final exam grade. High school GPA and critical thinking skills were the only variables that made a significant contribution to the prediction of final exam grade. High school GPA alone accounted for $15 \%$ of the variability in final exam grades. The addition of critical thinking assessed at the beginning of the semester to the equation, explained an additional $10 \%$ of the variability. A second step-wise multiple regression analysis was conducted to predict cumulative GPA from critical thinking skills pretest scores, SAT-V, SAT-M, and high school GPA. High school GPA emerged as the only variable that made a significant contribution to the prediction of cumulative GPA, accounting for $22 \%$ of the variability.

Goal 3 involved exploring whether taking an undergraduate level introductory psychology course taught using the TBL method would enhance student learning of course content, critical thinking skills, and academic self-efficacy compared to taking the course in a lecture-based format. We hypothesized that there would be a significant difference in critical thinking skills, academic self-efficacy, and course content knowledge between students who completed introductory psychology courses taught using a modified Team-Based Learning vs. traditional lecture-based method. Students' total CCTST and total ASE scores at the end of the semester (posttest scores) served as the measures of overall critical thinking and academic self-efficacy. An independent-samples t test was calculated to determine if there was a significant difference in overall critical thinking skills between the students enrolled in the two formats. The mean score for the total CCTST assessed at the end of the semester for the TBL group $(M=14.63, S D=4.58)$ was slightly higher than for the lecture-based group $(M=13.78, S D=4.59)$, but this difference was not significant, $t(103)=.94, p$ $=$.35. A second independent-samples $t$ test revealed no significant difference in overall academic self-efficacy at the end of the semester for students in the TBL format ( $M$ $=7.45, S D=1.46)$ and lecture-based format $(M=7.78$, $S D=1.39), t(108)=-1.23, p=.22$. Students' scores on a final cumulative exam (out of a possible 100 points) served as the measure of course content knowledge. An independent-samples $t$ test revealed no significant difference in final exam scores for students in the TBL format $(M=71.71, S D=14.57)$ and lecture-based format $(M=71.60, S D=15.14), t(127)=.04, p=.96$.

For goal 4 we were interested in whether or not there would be changes in students' critical thinking skills over the course of the semester and if the changes would be different for students enrolled in the lecture or TBL class formats. There was a significant albeit, small decline in CCTST scores over the semester, $t(103)=2.31, p<.05$. The decline in critical thinking scores was slightly larger for students in the lecture-based group $(M=-1.05, S D=4.07)$ than for students in the TBL group $(M=-.63, S D=3.52)$ but this difference was not significant, $t(.56), p=.58$.

Table 1. Means, Standard Deviations and Correlations Among CCTST, ASE, Final Exam Grade, Cumulative GPA and High School GPA

\begin{tabular}{|c|c|c|c|c|c|c|c|}
\hline & M & SD & 1 & 2 & 3 & 4 & 5 \\
\hline 1. CCTST Pre & 14.89 & 3.98 & - & & & & \\
\hline 2. CCTST Post & 14.15 & 4.58 & $.61^{* *}$ & - & & & \\
\hline 3. ASE Post & 7.64 & 1.43 & .01 & -.15 & - & & \\
\hline 4. Final Exam & 71.65 & 14.84 & $.37 * *$ & .18 & $.27^{*}$ & - & \\
\hline 5. Cum GPA & 2.83 & .75 & $.25^{*}$ & .08 & .19 & $.71^{* *}$ & - \\
\hline 6. HS GPA & 3.34 & .56 & $.26 * *$ & .04 & $.23^{*}$ & $.40 * *$ & $.46^{* *}$ \\
\hline
\end{tabular}

\section{Discussion}

The development of critical thinking in students is being increasingly emphasized as an important learning outcome across various disciplines in higher education. Critical thinking may be particularly important for students to be successful in courses that emphasize scientific inquiry and research methods such as an introductory level psychology course. Critical thinking may play an important role in college student learning and developing those skills warrant the attention of faculty members and instructors who strive to provide the best teaching and learning environments for their students. Teaching methods and instructional techniques should be 
explored to enhance the critical thinking of all students and its role in college academic performance.

Results from past research are not clear in terms of the magnitude of the relationship of measures of critical thinking skills to actual quantitative measures of academic achievement such as GPA in college students. Some researchers report small to moderate correlations between critical thinking skills and GPA or that critical thinking only accounts for a very small amount, less than $1 \%$ of the variance in GPAs. Additionally, academic self-efficacy has emerged as an important non-cognitive psychosocial variable that correlates moderately with academic performance. Therefore, one of the aims of the current study was to investigate the relationship of critical thinking and academic self-efficacy to final exam grade and GPA. There was a moderate correlation between critical thinking and final exam grade and a small correlation between critical thinking and GPA. These results are consistent with past researchers who have reported small to moderate correlations between critical thinking and similar academic outcome variables. It is noteworthy to mention that critical thinking along with high school GPA accounted for $25 \%$ of the variability in final exam grades. Furthermore, the fact that critical thinking skills alone, explained $10 \%$ of the variability in academic performance of introductory psychology students at the end of the course suggests that for our group of students, critical thinking skills are important for learning introductory psychology course content. This finding should not be surprising as it relates to the discipline of psychology. At our university, psychology is housed in the College of Science. Scientific thinking, research methods, evaluating claims, making sound judgments, drawing accurate conclusions based on data and scientific evidence, and analyzing results are all concepts that are taught and emphasized at the beginning of the introductory psychology courses. These concepts and skills are also reinforced and woven through the chapters that address specific content areas in the field of psychology. Some of these skills reflect components of critical thinking and others require individuals to rely on their critical thinking skills in order to develop them. Critical thinking skills appear to play an important role in learning content related to the scientific discipline of psychology.

Academic self-efficacy was not significantly related to overall academic performance but we found a positive, albeit small, correlation between academic self-efficacy and final exam grade for our sample. Past researchers have found moderate correlations between academic selfefficacy and college GPA but we did not obtain results consistent with these findings. One explanation for our results is that questions on the ASE, focus on students' perceptions of their abilities related to specific aspects of a course such as class concentration, note taking, and understanding concepts rather than measuring students' broad perception of academic self-efficacy. Since students were reporting about their course specific level of selfefficacy instead of overall academic self-efficacy, then it is not surprising that their scores were related to course specific academic performance (final exam performance) and not their overall academic performance as reflected by their cumulative GPA.
It was somewhat surprising that for our sample, high school GPA served as the only significant predictor of cumulative GPA and critical thinking skills and traditional measures of aptitude, SAT-V and SAT-M did not significantly predict college academic performance. It seems that for our introductory level students, their high school GPAs which may not only reflect past academic achievement but also motivation, study skills, time management capabilities, and other non-academic factors were most useful for predicting their academic performance. It should be noted that for our sample, the majority of the students were first year freshmen and their cumulative GPAs only reflected one semester of their performance in college. It would be interesting to see if this pattern remained the same for these students as they progressed through their college experience and whether or not HS GPA continued to serve as the best predictor of their academic performance at the end of their senior year. It may be that the curriculum becomes more challenging for students as they take more upper level courses. These upper level courses likely require students to rely more on their critical thinking skills to be successful. Therefore, overall critical thinking skills may be a better predictor of student academic performance at time of graduation than their performance earlier in their college careers.

Since being able to think critically and apply content knowledge to understand and solve real-world problems are important skills that are emphasized in higher education various tools and instructional methods have been developed to improve critical thinking in college students. Team-based learning has been emphasized in the teaching and learning literature as an effective instructional method that emphasizes critical thinking skills, the ability to analyze and apply content knowledge to aid in solving real-world problems, and fosters collaboration with others. We hypothesized that taking an introductory psychology course taught using the TBL method would lead to higher levels of critical thinking, academic self-efficacy, and content knowledge for students compared to those taking the course taught using a traditional lecture-based method. Although information from the TBL literature indicates that it improves educational outcomes for students in college courses [9], we did not see such improvements emerge in our study. There were no significant differences in students' critical thinking, academic self-efficacy, or final exam performance between students who took the course taught using TBL and students who completed the course taught using a lecture-based format. Students in the TBL sections did score slightly higher on the measure of critical thinking at the end of the semester compared to students in the lecture sections, but the difference was not significant. However, for both groups, there was a small decline in critical thinking scores over the semester, with the decline being slightly larger for students in the lecture-based courses, but the difference was not statistically significant. It was expected that students in the TBL sections would show superior performance on the final exam and increases in critical thinking skills and academic selfefficacy. While our findings were somewhat surprising there are several explanations for the results and still some important implications for the field of teaching and learning. 
First, it is important to emphasize that one semester may be too short a period of time to see significant changes in critical thinking and academic self-efficacy. Perhaps if students took multiple courses over several semesters taught using TBL, these changes may emerge. Therefore, studying the benefits of TBL using a longitudinal method is desirable for future research. The small decline in critical thinking scores at the end of the semester is puzzling especially since we might expect practice effects to lead to an increase in the scores. It is possible that students were "burned-out" at the end of the semester and saw no incentive or consequences for their performance on the CCTST. In contrast, at the beginning of the semester, because the students were unfamiliar with the instructors, course expectations, and the possible consequences and incentives associated with their performance on the CCTST, they may have put in more effort to perform.

There are a few possible explanations about why students in both methods performed equally well on the final exam. First, the TBL design used in this study was a modified version of the true TBL method. The primary difference between the modified TBL method used in this study and one that is followed with administrative strictness was that there were lecture classes given each week that correspond to each chapter covered throughout the semester. Therefore, lecture days for students in the TBL method were class periods that normally would have been spent on application activities. It is possible, that in order to see the strongest benefits to student learning throughout a semester, more days involved in applied activities are needed. Perhaps the procedural redundancy of using application activities in every class period is what is important to show significant gains in learning.

Secondly, because a significant portion of the semester was the same for students in both methods, they received the same lectures when there were "lecture days" for students in the TBL sections, there was not enough of a difference in the students experiences to see a difference in their performance on the final exam. Also, both authors consistently receive remarkably strong teaching evaluations for this course and it could be that their delivery of content leads to students successfully learning and retaining content knowledge regardless of any differences in course delivery (TBL vs. lecture). Furthermore, both authors use a number of real-world examples, discussions, and video clips in their lecturebased courses to help students connect course content to real-world experiences. Therefore, excellent teaching may be the key to student learning more so than just incorporating a particular method into a course; or at least any gains seen by a modified version of TBL may be limited. It would be interesting to see whether teaching using a TBL method would show better gains for instructors who are new to teaching and/or those who struggle when teaching courses through a predominantly lecture-based format.

Finally, the lack of significant results between the two methods could be due to the composition of students enrolled in introductory psychology courses. The majority of the students in the classes were freshmen. The TBL method has mostly been used in upper level undergraduate courses, graduate level course, and in medical school settings. For the TBL method to be truly effective, it requires that students take responsibility outside of class to read and study the material. We speculate that perhaps the preparation outside of class required for TBL to be most successful was not being carried out by a majority of the students because it was not a foremost priority for them. Most of the students enrolled in the introductory psychology courses were not psychology majors. It could be that students had to make choices about how to utilize their time outside of school and how much of it to devote to studying for classes within their major fields of study versus a general introductory course from the core curriculum. A student's particular major, level of interest in the field of psychology, and/or academic background could have influenced the amount of time and effort that an individual spent on the material outside of the classroom setting. Ultimately, it appears that for introductory level students, both methods (lecture and TBL) have merit and can both be used to accomplish course goals and important student learning outcomes.

Continued research on the importance of critical thinking as it relates to outcomes for students of all ages is warranted. Additionally, the exploration of instructional methods and course design that can enhance and foster the development and use of critical thinking and learning in general is also needed. Specifically, further investigation into the advantages of TBL within the discipline of psychology and with young undergraduate students in general may be worthwhile. Ultimately, it may be most important for professionals in higher education to continue to help students develop as well-rounded individuals by not only teaching content, enhancing cognitive and critical thinking skills, but also addressing psychosocial factors such as motivation, interest, self-efficacy, and study skills. We already know that college-age students in today's world can use technology to access information and facts quickly but this doesn't ensure that they are able to think critically with it or use it appropriately to solve real-world problems and to make important decisions. Our job as educators is constantly changing in today's world and we are being called upon to act more as facilitators, motivators, and mentors rather than content experts; roles that we may need to embrace more and more if we are to remain relevant to today's college students.

\section{List of Abbreviations}

ASE: Academic Self-Efficacy Questionnaire CCTST: California Critical Thinking Skills Test TBL: Team-Based Learning.

\section{References}

[1] Bandura, A. "Self-efficacy: Towards a unifying theory of behavior change”, Psychological Review, 84, 191-215. Mar. 1977.

[2] Bandura, A. "Self-efficacy mechanism in human agency" American Psychologist, 37, 122-147. Feb. 1982.

[3] Bycio, P., \& Allen, J. S., "The California Critical Thinking Skills Test and business school performance" American Journal of Business Education, 2(8), 1-8. Nov. 2009.

[4] Cotter, E. M., \& Tally, C. S., "Do critical thinking exercises improve critical thinking skills?” Educational Research Quarterly, 33(2), 3-14. Dec. 2009.

[5] Elias, S. M. \& MacDonald, S., "Using Past Performance, Proxy Efficacy, and Academic Self-Efficacy to Predict College 
Performance” Journal of Applied Social Psychology, 37(11), 2518-2531. Oct. 2007.

[6] Facione, P. A. (2000). California critical thinking skills test: Form 2000. Millbrae, CA: Insight Assessment.

[7] Facione, P. A., Facione, N. C., \& Winterhalter, K. (2010). California critical thinking skills test manual. Millbrae, CA: Insight Assessment.

[8] Gadzella, B. M., Baloglu, M., \& Stephens, R., "Prediction of GPA with educational psychology grades and critical thinking scores" Education, 122(3), 618-623. Mar. 2002.

[9] Haberyan, A., "Team-based learning in an industrial/organizational psychology course" North American Journal of Psychology, 9(1), 143-152. Mar. 2007.

[10] Halpern, D. F., "Teaching critical thinking for transfer across domains” American Psychologist, 53(4), 449-455. Apr. 1998.

[11] Michaelsen, L. K., Knight, A. B., \& Fink, L. D. (Eds.) (2004). Team-based learning. Sterling, VA: Stylus.

[12] Mone, M. A., "Comparative validity of two measures of selfefficacy in predicting academic goals and performance"
Educational and Psychological Measurement, 54(2), 516-529. Summer. 1994.

[13] Pike, G. R., \& Saupe, J. L., "Does high school matter? An analysis of three methods of predicting first-year grades" Research in Higher Education, 43(2), 187-207. Apr. 2002.

[14] Richardson, M., Abraham, C., \& Bond, R., "Psychological correlates of university students' academic performance: A systematic review and meta-analysis" Psychological Bulletin, 138(2), 353-387. Mar. 2012

[15] Robbins, S. B., Lauver, K., Le, H., Davis, D., Langley, R., \& Carlstrom, A., "Do psychosocial and study skill factors predict college outcomes?: A meta-analysis" Psychological Bulletin, 130(2), 261-288. Mar. 2004.

[16] Stupnisky, R. H., Renaud, R. D., Daniels, L. M., Haynes, T. L., \& Perry, R. P., "The interrelation of first-year college students' critical thinking disposition, perceived academic control, and academic achievement” Research in Higher Education, 49, 513530.

[17] Wood, R. E., \& Locke, E. A., "The relation of self-efficacy and grade goals to academic performance" Educational and Psychological Measurement, 47, 1013-1024. Winter. 1987. 